\title{
A CONTROVERSA RELAÇÃo DE J.-J. ROUSSEAU COM A REPÚBLICA DE GENEBRA
}

\author{
THE CONTROVERSIAL RELATIONSHIP BETWEEN J.-J. ROUSSEAU AND THE REPUBLIC OF \\ GENEVA
}

Vital Francisco Celestino Alves*

\section{RESUMO}

$\mathrm{Na}$ filosofia de Jean-Jacques Rousseau encontramos diversos elogios a modelos políticos oriundos da Antiguidade (Esparta e Roma), assim como outros elogios à República de Genebra. A esse último modelo, o pensador dedica a obra Discurso sobre a origem e os fundamentos da desigualdade entre os homens. Entretanto, até que ponto se pode afirmar que a ordenação política genebrina influenciou e contribuiu para a formação do pensamento político de Rousseau? Tendo essa questão como eixo central e objetivando produzir uma reflexão sobre a Genebra de Rousseau, o presente artigo pretende: primeiro, descrever como era a ordem política genebrina; segundo, tratar da relação entre Rousseau e Genebra; e, por último, correlacionar a posição que ocupa a cidade natal do autor com os seus escritos políticos apresentados na Dedicatória e no Contrato social e examinar a consistência das três principais linhas interpretativas que relacionam Genebra à filosofia política de Rousseau.

PALAVRAS-CHAVE: Rousseau. República de Genebra. Relação.

\begin{abstract}
In the philosophy of Jean-Jacques Rousseau we find several compliments to political models coming from Antiquity (Sparta and Rome), as well as other compliments to the Republic of Geneva. To this last model, the thinker dedicates the work Discourse on the Origin and Basis of Inequality Among Men. However, to what extent can one affirm that the political order of Geneva influenced and contributed to the formation of Rousseau's political thought? With this question as the central axis and aiming to produce a reflection on Rousseau's Geneva, the present article aims to: first, describe the Genevan political, second, deal with Rousseau's relationship with Geneva, and, finally, correlate the position the author's hometown occupies with his political writings presented in the Dedication and the Social Contract and examine the consistency of the three main interpretive lines relating Geneva to Rousseau's political philosophy.
\end{abstract}

KEYWORDS: Rousseau. Republic of Geneva. Relationship.

\footnotetext{
* Doutor em Filosofia pela UFG, com doutorado sanduíche na Université Montpellier III e no Centre Rousseau na Université Sorbonne, Paris III. Sou membro do Grupo Interdisciplinar de pesquisa Jean-Jacques Rousseau e do GT Rousseau e o Iluminismo. Professor assistente na UnB. E-mail: vitalalves1@ gmail.com.
} 


\section{INTRODUÇÃO}

A República de Genebra ${ }^{1}$, cidade natal de Jean-Jacques Rousseau, à qual ele se refere em várias passagens da sua reflexão política e dedica a ela a obra Discurso sobre a origem e os fundamentos da desigualdade entre os homens ${ }^{2}$, supostamente serviu de parâmetro político para a construção do seu ideário republicano. A "Dedicatória" que lemos antes do prefácio desse texto sugere uma admiração de Rousseau a Genebra e quiçá nos possibilita compreender um pouco acerca de suas preocupações com a ordenação republicana e como talvez o arquétipo genebrino tenha contribuído para o desenvolvimento da sua teoria política.

Presumivelmente Genebra oferece uma importante chave interpretativa para compreendermos as obras produzidas por Rousseau e uma senda que indica meios prováveis de lermos a Dedicatória e o Contrato social ${ }^{3}$. Mas a relação do autor com sua cidade de origem pode ser conferida, sobretudo, nas Cartas escritas da montanha ${ }^{4}$, obra em que Rousseau retoma as discussões políticas sobre o modelo de Genebra, manifesta vários de seus pontos de vista e aponta problemas inerentes à República na qual ele nasceu. Nesse sentido, talvez Genebra seja mais uma fonte capaz de contribuir no entendimento da teoria política de Rousseau, e quem sabe do seu republicanismo.

É importante lembrar que antes de qualquer intérprete destacar a relação entre Rousseau e Genebra, o próprio pensador chamou a atenção dos leitores para tal fato ao enfatizar orgulhosamente em um de seus notórios trabalhos políticos ${ }^{5}$ que era um "cidadão de Genebra”. Essa ênfase do nosso filósofo aguçou estudiosos de sua teoria a se debruçarem sobre o peso desse relacionamento e questionar o seu significado na formação da filosofia política de Rousseau. O modelo político genebrino foi perscrutado assim como a ligação de Rousseau com Genebra, principalmente, nas pesquisas de John Stephenson Spink (1934),

\footnotetext{
${ }^{1}$ Uma análise sobre a influência de Genebra no pensamento de Rousseau, segundo Christopher Bertram (2015) gira em torno de algumas dificuldades: em primeiro lugar, o fato de que existe uma sociedade real assim como uma ordem política legítima e constitucional. Isto é, trata-se de elementos distintos, visto que, da mesma maneira como sucede com todas as sociedades políticas, a maneira como as coisas procedem pode avizinhar ou afastá-las de como elas deveriam se concretizar. Em segundo lugar, existe a Genebra fruto da imaginação dos cidadãos comuns, da qual Rousseau parece ter compartilhado durante certo tempo. Em terceiro, existem as convicções pessoais do autor genebrino correlatas a Genebra e, finalmente, há a Genebra como foi retratada nos escritos rousseauístas. A explanação que será realizada acerca da controversa relação de Rousseau com o modelo político genebrino terá, inicialmente, como eixo interpretativo o artigo Rousseau e Genebra, de Christopher Bertram (2015).

${ }^{2}$ Doravante ao mencionar esse livro vamos chamá-lo apenas de Segundo Discurso.

${ }^{3}$ Essa obra gerou polêmica em Genebra e as duras críticas que sofreu levou Rousseau a escrever as Cartas escritas da montanha.

${ }^{4}$ Doravante chamaremos essa obra apenas de Cartas.

${ }^{5}$ Do contrato social.
} 
Robert Derathé (1950) e recentemente foi redescoberto por Helena Rosenblatt (1997) e Christopher Bertram (2015). Para compreendermos a controversa relação de Rousseau com a República de Genebra, buscaremos suporte teórico, principalmente, nas interpretações oferecidas por esses estudiosos.

\section{A ORDENAÇÃO POLÍTICA DE GENEBRA}

Seguindo o rastro interpretativo de Christopher Bertram (2015), pode-se considerar que no século XVIII Genebra era administrada a partir de decretos sancionados em 1543, os quais eram balizados, de maneira condensada, em um compêndio de princípios e condutas herdados do período medieval. De acordo com esses decretos, o poder em Genebra se dividia em quatro comitês: o Conselho Geral, o Conselho dos Duzentos, o Conselho dos Sessenta e o Pequeno Conselho. O Conselho Geral era constituído por todos os cidadãos e burgueses de Genebra, e os demais conselhos eram formados por partes de outros conjuntos de cidadãos. $\mathrm{O}$ Conselho Geral exerceu uma função proeminente no governo genebrino durante o regime episcopal; no entanto, no período da República, seus poderes diminuíram rapidamente e algumas de suas funções, como a de aumentar os tributos, acabaram sendo designadas a outros comitês.

Segundo Spink (1934), a partir desse momento, o Conselho Geral passou a se reunir raramente, mas como uma espécie de comissão assessora quando o Pequeno Conselho - que havia se tornado o corpo governante de Genebra - tinha algum tipo de dificuldade em tomar alguma decisão. Nesse sentido, mesmo preservando o poder de escolher os quatro representantes que comandariam a República, o Conselho Geral - que no regime republicano havia se tornado um corpo consultivo - se orientava por meio das tabelas imputadas pelo Pequeno Conselho.

Além disso, Genebra era uma sociedade de classes bem definidas. De sua população, em torno de 20.000 a 25.000 pessoas, somente entre 1.200 e 1.500 tinham direitos políticos ${ }^{6}$ assegurados, e eles eram os cidadãos e os burgueses, e entre eles só os primeiros, nascidos na cidade e filhos de pais cidadãos, gozavam do direito de serem eleitos para as funções públicas. Com efeito, a grande maioria da população não podia disputar os cargos públicos. É interessante notar que até no grupo que desfrutava de direitos políticos existia uma ramificação entre a elite patrícia rica e as outras partes. Os patrícios controlavam e

\footnotetext{
${ }^{6}$ A saber, somente $6 \%$ como assinala Bertram.
} 
governavam Genebra mediante o Pequeno Conselho e na sua efetiva participação nos dois conselhos intermediários.

Christopher Bertram sublinha que esse arranjo começou a ser pressionado no final do século XVII em decorrência de um motivo econômico e outro ideológico. O motivo econômico foi o fato de a burguesia ter se sentido ultrajada devido a uma série de ações do Pequeno Conselho, as quais abrangiam o fornecimento de alguns direitos comerciais a emigrantes e expatriados franceses e o favorecimento a genebrinos donos de vinhedos que moravam à margem do território da cidade. Quanto ao motivo ideológico, consistia em refutações à disseminação de um conjunto de concepções oriundas da Inglaterra, fundamentadas no pensamento político de John Locke que encontramos no Segundo tratado sobre o governo. O enfurecimento das classes comerciais tocante à comunidade política deflagrou três insurgências nos seguintes anos: 1707, 1734-8 e 1768. Na primeira dessas insurreições, Rousseau ainda não havia nascido; e em relação à segunda, ele a presenciou ao longo de uma visita a Genebra no ano de 1737 e, a terceira pode ser tida como um dos motivos para a sua insurreição às polêmicas que eclodiram com a censura do Contrato social.

As insurgências $^{7}$ de 1707 incluíram a figura de Pierre Fatio e o partido popular e tiveram como desdobramento a rejeição do Pequeno Conselho perante uma investida no encorajamento de inúmeras ações de cunho democrático, que compreendia a proposição advogada por Fatio - de assembleias anuais do Conselho Geral visando estipular e rever as leis e os decretos. O Pequeno Conselho concordou com várias reformas, entre elas a fixação de uma assembleia quinzenal do Conselho Geral. Porém, com o esteio de tropas de Zurique e Berna, o Pequeno Conselho enclausurou os dirigentes do partido popular e assassinou Fatio. Como consequência, escreve Bertram, a solicitação por assembleias periódicas foi rechaçada na primeira assembleia quinzenal do Conselho Geral. Depois disso, a facção burguesa adotou a postura de que, considerando que o Conselho Geral era detentor do título de soberano, ela tinha o direito de desempenhar o poder hegemônico no Estado. Em 1734, temendo a crescente ascensão da facção burguesa, o partido patrício se organizou com o intuito de desmantelar o poderio burguês, mas não foi bem sucedido. A segunda investida, apoiadas pelos nativos, desencadeou uma batalha frontal entre burgueses e patrícios em 1737. Com a mediação da França, Berna e Zurique, ficaram definidos por decreto em 1738 os poderes dos múltiplos conselhos, que se encontravam legitimamente vigentes quando Rousseau escreveu a

\footnotetext{
${ }^{7}$ Continuaremos seguindo a vertente interpretativa de Bertram.
} 
Dedicatória que lemos no Segundo discurso, na época em que pleiteou a revalidação de sua cidadania em 1754 e, sobretudo, quando produziu a Carta a D'Alembert e o Contrato social.

O decreto oriundo da mediação suscitou e ressaltou a leitura dos patrícios acerca da constituição de Genebra, contudo, na visão de Bertram, efetivou concomitantemente o reconhecimento do Conselho Geral como Conselho Soberano e o compreendia como o depositário dos poderes legislativo, eletivo e confederativos, mas que, em termos lícitos, ao reverso, lhe eram contraditos pelos pormenores do documento. No sentido jurídico, o Conselho Geral não tinha o direito de iniciativa legislativa, seu direito ao voto se restringia aos candidatos apresentados pelo Pequeno Conselho, e mesmo que a facção burguesa ainda tivesse o direito de empregar representações divergentes ao Pequeno Conselho, lhe havia sido retirado o direito de se unir, e por meio de algum estatuto angariar forças para viabilizar essas representações, tornando engessada a possibilidade de a burguesia se tornar um perigo real ao poder dos patrícios. Por conseguinte, o Pequeno Conselho conservou para si o direito de decidir quais providências tomar concernentes às representações e, mais do que isso, o direito de escolher se transmitiria ou não seu juízo a respeito delas ao Conselho Geral.

\section{A RELAÇÃO ENTRE ROUSSEAU E GENEBRA}

Tendo em vista a exposição realizada no tocante ao funcionamento político de Genebra, cabe, a partir de agora, nos determos, ainda que brevemente, na relação entre Rousseau e Genebra. Na Carta a d'Alembert, o filósofo reaviva a memória afetiva de quando abandonou a cidade aos dezesseis anos, em 1728, e lembra que o seu convertimento ao catolicismo acarretou a perda de sua cidadania. Sabemos também pelos relatos de Rousseau que ele visitou Genebra em 1737, não obstante, nos parece que foi somente entre 1728 e 1754 que ele teve interesse em visitar sua cidade de origem. Logo após esse período, em 1754, o nosso autor elaborou a célebre Dedicatória, em que enaltece ${ }^{8}$ a constituição política de Genebra. Depois de 1754, Genebra adquire relevância em seu pensamento devido a dois acontecimentos: o primeiro em função de sua resposta, em 1758, ao verbete de d'Alembert a respeito de Genebra na Encyclopédie, e o segundo referente às Cartas escritas da montanha, de 1764, escritas para refutar Tronchin. Somando a esses dois momentos, adiciona-se a publicação do Contrato social, posto que, nas Cartas, Rousseau declara que o contrato é a

\footnotetext{
${ }^{8}$ Ou parece elogiar, segundo Bertram.
} 
expressão de uma apologia aos fundamentos primordiais do sistema político genebrino. No Contrato social observamos uma franca menção a Genebra em uma nota de rodapé ${ }^{9}$ presente no capítulo em que Rousseau analisa o pacto social. Nessa nota, vemos sugestões direcionadas ao governo, como as assembleias fixas e periódicas do povo e a iniciativa legislativa pelos magistrados, índice que, inevitavelmente, nos parece reverberar a conjuntura política de Genebra ou os anseios de uma classe dos genebrinos. Como se sabe, o Contrato social foi criminalizado pelo Pequeno Conselho em Genebra e, consequentemente, incinerado. Esse fato parece ter deixado Rousseau aturdido. É notório também que as autoridades de Genebra selecionaram claramente os pontos para fundamentar a condenação, sustenta Bertram, pois elas confrontaram a heresia religiosa vista no capítulo acerca da Religião civil, o que foi uma estratégia de difamar o nome de Rousseau e fazer com que os genebrinos populares o vissem como alguém situado abaixo de um cristão. Posteriormente, o filósofo buscou reintegrar sua imagem como cristão na Carta a Christophe de Beaumont, todavia, novamente sofreu uma condenação. Diante dessa condenação, Rousseau se viu obrigado a abdicar de sua cidadania com pesar. Somente, em seguida, tendo sido impelido por simpatizantes da burguesia de Genebra, estarrecidos com o trato devastador que lhe foi conferido, Rousseau se mobilizou para incendiar uma controversa vis-à-vis com os mandatários oficiais dos patrícios e escreveu as Cartas escritas da montanha.

\section{A SUPOSTA INFLUÊNCIA DA REPÚBLICA DE GENEBRA NOS ESCRITOS POLÍTICOS DE ROUSSEAU}

Em virtude do que foi discorrido até aqui, convém analisar o peso da suposta influência da República de Genebra na elaboração dos pilares cruciais da teoria política de Rousseau. Para tanto, nos orientaremos pela Dedicatória e pelo Contrato social. Quando se lê a Dedicatória a República de Genebra narrada por Rousseau no início do Segundo discurso, testemunha-se uma verdadeira reverência do autor a sua cidade natal, a presença das referências oriundas da Antiguidade: as cidades de Atenas e Roma e dos admirados autores Tácito e Plutarco. Simultaneamente, podem-se atestar temas fundamentais no seu pensamento tais como: a igualdade, a liberdade e a soberania popular. Em sua Dedicatória, o pensador genebrino descreve como gostaria que fosse o lugar do seu nascimento caso ele pudesse

\footnotetext{
${ }^{9}$ Especificamente na nota 4 do capítulo VI, do "Primeiro livro". Nesta o filósofo genebrino trata da verdadeira acepção do termo "cidade" e elogia D'Alembert por ter compreendido o verdadeiro significado da palavra "cidadão".
} 
escolher. Sua descrição passeia por temas também recorrentes no seu pensamento, mas nesse texto Rousseau mira diretamente Genebra.

Consideramos razoável a tentativa de deslindar a teoria política rousseauísta mediante a sua ligação com Genebra, ligação que, a nosso ver, se conservou por um tempo significativo $^{10}$. Seguramente podem-se estabelecer algumas prováveis aproximações entre a Constituição de Genebra e o Contrato social, contudo, entende-se, à primeira vista, que defender que esse modelo político teve uma influência equivalente à de Esparta e Roma na formação do pensamento de Rousseau se configura uma interpretação desacertada, a qual foi bastante utilizada por alguns opositores ${ }^{11}$ do autor genebrino, justamente para desqualificar a força e a relevância de seu escrito político, como bem realçou Derathé.

Buscando sustentar a hipótese da influência da República de Genebra, tentou-se procurar apoio nas próprias declarações de Rousseau. Afinal, não foi ele mesmo que afirmou em Rousseau juiz de Jean-Jacques que "havia trabalhado por sua pátria e pelos pequenos Estados constituídos como ela"? ${ }^{12}$ E quem também exprimiu nas Cartas que a obra o Contrato social comportava "a história do Governo de Genebra" e que nela os genebrinos visualizariam claramente as particularidades da sua República? Nas palavras do pensador: adotei vossa constituição, que acho bela, como modelo das instituições políticas (ROUSSEAU, 1964, p. 809, tradução nossa) ${ }^{13}$. Nesse caso, ao produzir o Contrato social, Rousseau teria, como referência a partir das suas próprias palavras, unicamente Genebra e a sua constituição como fonte de seus fundamentos políticos.

Segundo Derathé (1950), essa hipótese, que por um espaço de tempo ${ }^{14}$ considerável teve notabilidade, não se sustenta em face de uma análise mais severa. Para comprovar essa assertiva, o comentador reporta à argumentação que Spink (1934) apresenta em Jean-Jacques Rousseau et Genève, na qual explicita que no período em que Rousseau redigiu o Contrato social ele desconhecia a constituição de Genebra ou a conhecia superficialmente. Para corroborar sua tese, Spink evoca elementos históricos ${ }^{15}$ peremptórios, enquanto Derathé, por

\footnotetext{
${ }^{10}$ A saber, até o momento da ruptura. Depois disso, o amor que Rousseau alimentava por Genebra transformouse em indiferença. Ver mais em Jean-Jacques Rousseau et la Science politique de sons temps, p. 8, nota 2, Robert Derathé (1950).

${ }^{11}$ Ver mais em Jean-Jacques Rousseau, de Jules Lamaître (1925); L'Europe et la Révolution, de A. Sorel (1893) e L'Espirit de la Révolución française, de E. Champion (1887).

12 Terceiro diálogo (IX, 287).

13 “J'ai donc pris votre constituion, que je trouvais belle, pour modele des instituions politique". (CDM, L VI. OCR3).

${ }^{14}$ Sustentada irrestritamente, por exemplo, por Lanson (1920).

15 A saber, a Carta a Rey, de 7 de novembro de 1761, C. G., no 1170, t. VI, p. 288 e o trecho das Confissões no qual Rousseau explica como fecundou o plano de redigir suas Instituições políticas, dito pelas palavras de
} 
uma via distinta, chega à mesma conclusão. Deve-se admitir que o caminho seguido por Derathé - aferir os princípios do direito político do Contrato social com os da Constituição de Genebra, almejando verificar se eles estão em conformidade -, é aquele que mais pode contribuir para o nosso exame.

$\mathrm{O}$ autor de Jean-Jacques Rousseau et la science politique de son temps sustenta que a Dedicatória de Rousseau a Genebra que lemos no Segundo discurso expressa quando não um desconhecimento, uma ingenuidade do filósofo. O próprio Rousseau demonstra esse fato ao examinar pormenorizadamente a constituição de Genebra para escrever as Cartas escritas da montanha. Nessa última obra, vemos uma explanação firme que passa longe da exaltação pueril vista na Dedicatória. O cotejamento entre os dois escritos, redigidos com cerca de dez anos de diferença, atesta a profunda transformação da visão de Rousseau sobre a ordem política de Genebra, posto que ele a havia analisado detidamente. Derathé assinala que se em 1754 Rousseau encontrava-se eufórico por ser recepcionado em Genebra para resgatar seu título de cidadão, esse contentamento afetuoso em relação à pátria é claramente renunciado em 1764 quando o desencanto provocado por seu regresso a Genebra e a perscrutação detalhada de sua constituição fizeram-no enxergar a sua cidade natal de outra forma.

A relação de Rousseau com Genebra, como se nota, é bastante controversa. Helena Rosenblatt (1997) defende que até 1934 a relevância de Genebra na formação da teoria política de Rousseau era praticamente desconhecida. Os estudos anteriores a esse período, porém, foram prejudicados por uma compreensão superficial acerca da história de Genebra e do Calvinismo. Neles há a ausência de uma análise mais apurada, e a avaliação do papel dos políticos costuma ser empreendida apressadamente e de maneira generalizada, sem recorrer aos textos de Genebra. A intérprete toma como exemplo a leitura de Gaspar Vallette (1912), para ele o pensamento de Rousseau é genebrino, e o Contrato social é um livro sobre Genebra e sobremaneira inspirado na constituição de Genebra e na sua propensão à democracia. Outros pesquisadores ${ }^{16}$ reconhecem o Contrato social como uma apologia ao modelo de constituição de Genebra. Tais apreciações, entretanto, segundo Rosenblatt, são imaturas e correlatas. Quanto ao ambiente de Genebra tendem a se inclinarem a uma visão indistinta das concepções rousseaunianas.

Rousseau: "Percebia que tudo isso me levava a grandes verdades, úteis à felicidade do gênero humano mas, sobretudo, à de minha pátria, onde não tinha encontrado, na viagem que acabara de fazer, as noções das leis e da liberdade, a meu grado nem suficientemente justas nem suficientemente claras"' (VIII, 289).

${ }^{16}$ Ver A. Gür (1981). 
J. Spink (1934) assume uma postura dissonante no que diz respeito às interpretações reducionistas que o precedem. Em sua opinião, o Contrato social é uma obra genuinamente especulativa, na qual o autor procura investigar os princípios da lei pública. Spink contesta veementemente o pressuposto de que a obra especificada seja concebida como uma mera exaltação à constituição de Genebra. De acordo com o pesquisador, não se pode impingir à constituição mencionada um sentido especial na teoria de Rousseau antes da reprovação de Genebra ao Contrato social, pois o nosso pensador tinha um conhecimento bastante parco concernente aos tempos mais remotos de Genebra antes da condenação de sua obra. Em poucas palavras, a tese de Spink almeja romper com o vínculo entre a perspectiva política de Rousseau e a constituição de Genebra; apesar disso, o comentador defende que a burguesia genebrina talvez tenha desempenhado uma sintomática influência na percepção política rousseauísta e presume que somente em Genebra Rousseau pode ter desenvolvido seu orgulho e espírito republicano. Ademais, o intérprete julga que Rousseau não compreendia a ordenação política de Genebra, e tampouco discutia política com amigos de sua terra natal antes de $1764^{17}$. Em função dessa incompreensão, antes desse ano sua visão concernente ao sistema político de Genebra sobrevoa nos ares do senso comum.

Essa hipótese de Spink repercute na clássica leitura de Robert Derathé (1950). Esse último concorda com Spink no tocante ao fato de que antes de 1762 Genebra não integra o repertório de suprema fonte de influência nas noções políticas de Rousseau. Derathé advoga que os conceitos democráticos rousseauístas e o arranjo político de Genebra não possuíam similaridades. Nos termos do comentador:

Genebra teve sem dúvida um grande espaço na imaginação e na vida de Rousseau, mas é em outro lugar que devemos buscar as fontes de seu pensamento político, como indica muito claramente M. Spink (DERATHÉ, 1950, p. 22, tradução nossa) ${ }^{18}$.

Avaliar se a constituição de Genebra serviu de cânone político para Rousseau - ainda considerando a análise de Derathé - foi uma tática dos oponentes de Rousseau com a evidente pretensão de apequenar a relevância de sua filosofia política. O Contrato social é uma obra

\footnotetext{
${ }^{17}$ Ano da publicação das Cartas escritas da montanha. Texto escrito devido à condenação do Contrato social e do Emílio que começou no parlamento francês, praticamente, ao mesmo tempo em que na cidade de Genebra surgiu uma perseguição semelhante que teve seu apogeu na condenação das obras pelos pastores genebrinos. Nas Cartas, Rousseau estabelece uma refutação às inúmeras críticas recebidas e, concomitantemente, realiza uma análise do funcionamento das instituições políticas de Genebra e nos apresenta uma perspectiva condensada e madura de sua filosofia política.

18 “Genève a tenu sans aucun doute une grande place dans l'imagination et dans 1 avie de Rousseau, mais c'est ailleurs que nous devons chercher les sources de as pensée politique, comme l'indique três clairement M. Spink".
} 
atemporal, logo é perfeitamente plausível não vê-la simplesmente como um texto de inspiração genebrina.

Em certa medida, alguns biógrafos de Rousseau atestam a posição de Spink e Derathé ao sustentarem que o autor não compreendia a constituição de Genebra antes de 1762. Maurice Cranston (1982) assevera, por exemplo, que Rousseau tinha sido erroneamente levado a acreditar que Genebra era uma República ideal; R. Trousson (1988) confirma que a visão de Rousseau sobre Genebra não passa de um mito, e, Guehénno (1962) testifica que na época em que Rousseau havia se tornado um escritor célebre, Genebra se configurava apenas em uma irrisória reminiscência infantil ${ }^{19}$, uma fantasia, uma Genebra que existia somente nos sonhos de Rousseau.

Outro ponto de vista interpretativo que vale mencionar é o de Michel Launay (1971). Em seu livro Jean-Jacques Rousseau écrivan politique, Launay apresenta Rousseau como um porta-voz da pequena burguesia genebrina que se opunha ao patriciado de Genebra. Na percepção de Rosenblatt, por conter informações preciosas acerca de Genebra, a leitura de Launay tem sua importância. Porém, minimiza a relevância da tradição intelectual genebrina, pois o intérprete alega que mesmo tentando romper com uma visão política tradicional, Rousseau permanece arraigado a ela.

$\mathrm{Na}$ percepção de Launay, o pensamento político rousseauniano é cercado por ambivalências porque há uma negação da consciência de todas as classes sociais que constituíam a ordem política de sua cidade natal. E é justamente Genebra que explicita a ambiguidade tradicional presente na filosofia de Rousseau. O estudioso acrescenta também que o pensamento de Rousseau apenas adquire importância e autenticidade quando o autor rompe com a conjuntura de Genebra. Contrapondo a Launay, Helena Rosenblatt afirma que essa interpretação deixa a desejar porque não analisa com profundidade o que denomina de mentalidade tradicional em Rousseau e reduz a infraestrutura política de Genebra; por exemplo, ao retratar os pastores como "macacos e condes da classe superior"20.

Rosenblatt destaca que uma análise expressiva nesse sentido foi realizada por A. Gür (1981). Ele demonstra que o mais significativo compêndio político em defesa da burguesia na história de Genebra teve como principal representante um proeminente pastor, e que inúmeras ideais reconhecidas até hoje como sendo contribuições do pensamento político de Rousseau já

\footnotetext{
${ }^{19}$ Ver mais em Maurice Craston, The early life and work of Jean-Jacques Rousseau - 1712 a 1754, University off Chicago Press. (1982), p. 324; R. Trousson, J.-J. Rousseau, la marche à la glorie (1988), p.37, e, J. Guehénnon, Jean-Jacques Rousseau (1962), p. 117.

20 "monkeys and valets of the upper class", Helena Rosenblatt (1997), p. 48. (tradução nossa).
} 
existiam em Genebra bem antes do autor do Emílio. Rosenblatt também se refere ao trabalho de R. Fralin (1978). Segundo Fralin, alguns dos conceitos mais notórios de Rousseau têm sua gênese em Genebra e isso pode ser constatado no Contrato social. Nos termos de Fralin (1978, p. 44):

Genebra era ambos: o ponto inicial e o ponto final, a inspiração e o objetivo do pensamento político de Rousseau e com o tempo ele escreveu o Contrato Social. (tradução nossa) $^{21}$.

Entretanto, lamenta Rosenblatt, Fralin não esquadrinha o contexto político de Genebra que precede Rousseau e nem mesmo cita o Calvinismo como provável pano de fundo da relação entre Rousseau e Genebra. ${ }^{22}$

Julgamos que o esforço de Fralin consiste em relacionar o pensamento institucional de Rousseau com a musculatura política de Genebra. Ele argumenta que a compreensão rousseauniana sobre a representação era imprecisa. Imprecisão que refletia as dubiedades da constituição de Genebra. Ao mencionar a influência de Genebra, Fralin a entende como a genealogia de algumas concepções assumidas por Rousseau. Tal proximidade, todavia, defende Rosenblatt, restringe a discussão sobre a influência de Genebra e suas afinidades com a teoria política rousseauísta.

\section{TRÊS LINHAS INTERPRETATIVAS}

Recuperando o fio da meada interpretativa de Christopher Bertram (2013) temos, em síntese, três escolas que tratam da relação entre a filosofia política de Rousseau exposta na Dedicatória e no Contrato social e Genebra. A primeira delas, Bertram identifica como ingênua e ignorante e é encabeçada por Spink e Derathé. Essa escola defende a tese de que, quando Rousseau formulou esses trabalhos, ele desconhecia a autêntica constituição de Genebra. Sendo assim, as suposições de que as obras correspondem ou são inspiradas pelo arquétipo político genebrino devem ser recusadas. É possível que Rousseau tenha criado um quadro colorido de sua pátria baseado nos anos de sua meninice, quadro esse que desemboca na idílica Dedicatória e na perplexidade do autor em vista da reação de Genebra acerca do

\footnotetext{
21 "Geneva was both the starting point and finishing point, the inspiration and the goal of Rousseau's political thought at the time he wrote the Contrat Social".

${ }^{22}$ Para Rosenblatt, ao omitir o elemento religioso Fralin reduz outras noções cruciais, tais como a vontade geral, noção crucial na filosofia de Rousseau, que como explicitaram Bertrand de Jouvenel (1947) e P. Riley (1986) é dotada de raízes teológicas.
} 
Contrato social, no entanto, a verdadeira fonte de ímpeto criativo para sua teoria política deve ser reportada a outras fontes, acima de tudo na tradição do pensamento político e na teoria do direito natural.

A segunda perspectiva, verificada com distintas variações em intérpretes como Michel Launay, Helena Rosenblatt, Blaise Bachofen (2002), é denominada por Bertram de polêmica oculta. Conforme essa linha interpretativa, Rousseau tinha o conhecimento claro da peculiaridade oligárquica da constituição de Genebra e a refutava e, efetivamente, apoiava vários pontos da visão do partido popular. O panegírico a Genebra que encontramos na Dedicatória, desse modo, não deve ser entendido como uma manifestação prudente de Rousseau a respeito de Genebra, mas sim como uma espécie de controvérsia refinada na qual o autor destila uma crítica frontal à oligarquia e que só poderia ser compreendida pelos habitantes de Genebra. A terceira interpretação, estabelecida por Fralin, defende que realmente as instituições políticas pertinentes a Genebra tiveram forte influência na composição dos conceitos rousseauístas. Bertram chama essa visão de conservadora tácita. Ela apregoa que mitiguemos a tensão entre a Genebra real e o regime democrático temperado, conquanto indaga a consistência de Rousseau com os princípios democráticos. A perspectiva polêmica oculta e a conservadora tácita sinalizam que não deveríamos julgar o posicionamento de Rousseau como realmente crédulo, ou seja, que é inviável conceber o autor como simplesmente alguém que não é um admirador de Genebra e tenciona ser ou alguém que apenas defende a soberania popular, pois o Contrato social é mais complexo e controverso do que se vê na aparência.

Para Bertram essas visões são dotadas de argumentos robustos que servem de sustentáculos para suas defesas. Ultrapassando o aspecto controvertido como seus expoentes constantemente mencionam uns aos outros, tais concepções acabam se situando, de maneira recíproca, aquém das incompatibilidades aparentes. Desejando confirmar essa posição, Bertram toma à guisa de exemplo a interpretação de Spink. Esse comentador não tem dificuldade em demonstrar a antinomia entre aquilo que Rousseau declara e a constituição de Genebra à custa de uma explanação minuciosa da história constitucional da pátria originária de Rousseau. A antinomia entre a realidade e a ilusão mantém-se inalterada mesmo quando o filósofo genebrino adquire uma compreensão do arranjo político, visto que ele parece insistir em consolar a si mesmo com o pressuposto de que foi uma insurgência progressiva e bastante sútil da soberania popular pela oligarquia o que se sucedeu em Genebra. 


\section{CONCLUSÃO}

Supondo que tenhamos cumprido objetivos fixados no começo dessa jornada investigativa, cabe, a partir deste momento, apresentar um desfecho para a nossa explanação. A análise realizada nos possibilitou entender as razões pelas quais o Contrato social foi condenado em Genebra. Em face da acusação, Rousseau poderia, indubitavelmente, apelar para o cunho filosófico e abstrato de sua obra, mesmo assim o livro continuaria dando à classe burguesa uma ferramenta ${ }^{23}$ amedrontadora em contraposição ao partido governamental. Avaliando a função desempenhada pelo Contrato Social na política e nas contendas genebrinas, ao reverso, compreende-se que o escrito não tem Genebra como inspiração. Rousseau o formulou desconhecendo detalhes decisivos da constituição de sua cidade natal e na ocasião em que se viu no dever de examiná-la pôde constatar como ela encontrava-se longínqua dos princípios do direito político que lemos no Contrato social.

Pode-se comprovar também que no contexto da polêmica de Rousseau com Genebra a cidade podia ser vista como uma aristocracia balanceada pela democracia, uma vez que a constituição negava ao Conselho geral o direito de se reunir por iniciativa própria. O elogio que Rousseau faz a Genebra na Carta a d'Alembert e na Dedicatória revela um equívoco cometido pelo amor que ele cultivava pela sua cidade de origem e, visualizando-a mediante sua imaginação, julgou ter visto nela o seu mais perfeito modelo democrático. É inegável que Genebra ocupa um lugar privilegiado na existência de Rousseau; não acreditamos, apesar disso, que a Dedicatória retrate de maneira fidedigna o governo genebrino e que o Contrato social explicite fundamentos políticos inspirados em Genebra, o que se pode dizer é que houve um instante no qual Rousseau, de fato, acreditou que havia em Genebra instituições políticas compatíveis com o seu ideal republicano.

Genebra tem sua relevância na filosofia de Rousseau, porém a cidade que fomenta, frequentemente, o pensamento do autor não corresponde à Genebra da realidade, mas sim àquela que ele projetou com sua imaginação. A Genebra real não era um arquétipo político de consonância com a teoria rousseauísta. É bem provável que Rousseau tenha absorvido um mito acerca da realidade genebrina assaz disseminado e partilhado pela classe burguesa, mito este envolto oniricamente por um desejo de soberania popular que foi de maneira gradativa demolida pelos magistrados. Rousseau parece ter deliberado por encaixar Genebra fora da sua

\footnotetext{
23 As assembleias fixas e periódicas apresentadas no Contrato social comparadas a conjuntura política de Genebra, demarca a posição de Rousseau ao lado dos burgueses e oposto ao partido do governo.
} 
realidade política e nutrir a esperança de que o declínio previsível fosse impedido. Observa-se que suas ações políticas foram influenciadas por essa postura fantasiosa e talvez, devido a isso, notamos nos seus textos relacionados a Genebra um estranho conservadorismo que diverge categoricamente do teor revolucionário presente no seu ideário político republicano.

\section{REFERÊNCIAS}

BACHOFEN, B. La condition de la liberte: Rousseau, critique des raisons politiques. Paris: Payot, 2002.

BERTRAM, Christopher. Rousseau e Genebra. Trans/Form/Ação. Vol. 38, Marília-SP, 2015.

CHAMPION, E. L’Espirit de la Révolución française. Paris: Reinwald, 1887.

CRANSTON, Maurice. Jean-Jacques: the early life and work of Jean-Jacques. The University of Chicago Press, 1982.

FRANLY, R. Rousseau and Representation. New York: Comumbia, 1978.

DERATHÉ, Robert. Jean-Jacques Rousseau et la Science politique de son temps. Paris: VRIN, 1950.

GUEHENNO, Jean. Jean-Jacques Rousseau. London: Routledge, 1962.

GÜR, A., "Les lettre 'séditieuses' anonymes de 1718, étude de texte," BSHAG, 17, 2, 1981, pp. 129-205.

JOUVENEL, Bertrand de. Essai sur la politique de Rousseau. Paris: Hachette, 1947.

LAMAÎTRE, Jules. Jean-Jacques Rousseau. University Michican, Calmann-Lévy, 1925.

LANSON, G. Histoire de la littérature française, 14. édit. Paris, Hachette, 1920, in-16

(Cinquième Partie, liv. IV, chap. V).

LAUNAY, M. Jean-Jacques Rousseau, écrivan politique. Grenoble: CEL/ACER, 1971.

LOCKE, John. Dois tratados sobre o governo. São Paulo: Martins Fontes, 2001.

RILLEY, P. The general will before Rousseau. Princeton: Princeton University Press, 1986.

ROSENBLATT, Helena. Rousseau and Genebra - From the first discourse to the social contract, 1749-1762. Cambridge University Press, New York, 1997.

ROUSSEAU, J.-J. Oeuvres complètes. Paris, 1959-1995. (5 Volumes).

ROUSSEAU, J.-J. Cartas escritas da montanha. São Paulo: Unesp, 2006. 
ROUSSEAU, J.-J. Carta a D’Alambert. São Paulo: Unicamp, 1993.

SOREL, Albert. L'Europe et la Révolution française. Paris: E. Plon, Nourrit et cie, 1893.

SPINK, J.S. Rousseau et Genève. Paris: Bovin, 1934.

TROUSSON, R. Jean-Jacques Rousseau, la marche à la glorie. Paris, 1988.

VALETTE, Gaspar. Jean-Jacques Rousseau Genevois. Paris and Geneva, 1912. 